\title{
Differential Pulse Voltammetric Determination of Clozapine in Drug Dosage Forms at Bismuth Film Electrode
}

\author{
Ozlem Kurtoglu Yigit ${ }^{(\mathbb{D}}$ Ebru Gokmese ${ }^{(\mathbb{D}}$ Faruk Gokmese \\ Hitit University, Department of Chemistry, Corum, Turkey
}

\section{A BSTRACT}

A new differential pulse voltammetric method for the determination of clozapine in drug dosage forms has been described. In this study, the amount of clozapine in commercial forms has been determined at bismuth modified glassy carbon electrode by taking advantage of the electrochemical oxidation of it. The glassy carbon electrode was modified with $\mathrm{BiCl}_{3}$ to prepare the bismuth film electrode. The acetate buffer solution at $\mathrm{pH}=5.00$ was selected as the supporting electrolyte in where the maximum current was observed for clozapine at the bismuth film electrode. The effect of $\mathrm{pH}$ on peak current and peak potential of clozapine was investigated by differential pulse voltammetry (DPV), and the effect of scan rate on the peak current was examined by cyclic voltammetry $(\mathrm{CV})$. With this developed voltammetric method, the detection limit for clozapine in the working range of $1 \mu \mathrm{M}$ and $10 \mu \mathrm{M}$ was found to be $6.112 \times 10^{-9}$. The amount of clozapine in the drug tablets was stated after the determination of analytical parameters. The recovery study was executed to check the accuracy and precision of the applied method.

\section{Keywords:}

Clozapine; bismuth film; drug analysis; modified electrode; differential pulse voltammetry

\author{
Article History: \\ Received: 2021/01/20 \\ Accepted: 2021/03/06 \\ Online: $2021 / 03 / 31$
}

Correspondence to: Ebru Gokmese, Hitit University, Department of Chemistry,

19030, Corum, Turkey

E-Mail:ebrugokmese@hitit.edu.tr

Phone: +903642277000

Fax: +903642277005

\section{INTRODUCTION}

Clozapine, which has a heterocyclic structu$\checkmark$ re is 8-chloro-11-(4-methyl-1-piperazinyl)$5 \mathrm{H}$-dibenzo-diazepine and Fig. 1 shows the chemical structure of this compound [1,2]. Clozapine, which is a strong antipsychotic agent from the dibenzodiazepine group, is called a typical antipsychotic since it has typical pharmacological and clinical features. Many studies comparing clozapine with traditional antipsychotics have shown that clozapine is at least as effective as traditional antipsychotics, even in some cases, this effect has increased [3].

Clozapine has been used in the treatment of patients with schizophrenic resistant to treatment who are caused by neuroleptic drugs that block the typical D2 receptor and develop unsuccessful physiological conditions. Also, clozapine treatment as in conventional antipsychotics stops the abnormal movements of Tardive dyskinesia and clozapine can additionally cure the defect of movement. On the other hand, clozapine is partially active in the treatment of tardivdistonia [4, 5]. Clozapine is also used to treat some schizophrenic patients cannot be treated by traditional neuroleptic drugs. Since the analysis of clozapine in pharmaceutical and chemical liquids is important, different analytical methods such as chromatography [6,7] and spectrophotometry [8] have been used to determine dosage forms. Studies on the therapeutic and toxic effects of drugs have shown that sensitive methods are required to obtain results at the trace level. The sensitivity of the studies with spectroscopic methods is not sufficient. Voltammetric and polarographic studies of the electrochemical behavior of clozapine are available in the literature $[9,10]$. To date, techniques for the detection of clozapine, including high-performance liquid chromatography, spectrophotometry, chemiluminescence, capillary electrophoresis, and titrimetry, are available $[11,12]$. These methods, however, are exhausting, costly, and require the pretreatment of samples. On the other hand, electrochemical techniques such as voltammetry supply a wide linear working range as well as high precision, low cost, and high accuracy. Therefore, studies on the electrochemistry of drugs have increased in recent years [13, 14]. Since clozapine is a good electroactive substance, electroanalytical results of oxidation behavior in different electrodes have been described $[15,16]$.

Electrochemical techniques are strong and multipurpose analytical techniques that can easily solve many pharmaceutical-related problems. Especially vol- 


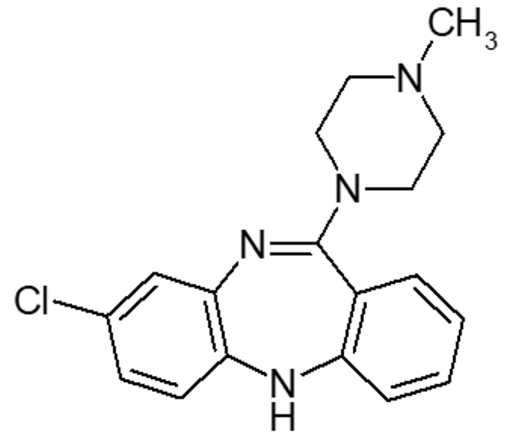

Figure 1. The chemical structure of Clozapine

tammetry is an effective electrochemical analytical technique with high sensitivity, selectivity, large linear range, and low-cost devices. Although there are studies on the oxidation behavior of clozapine in the literature, no studies have been found with bismuth film electrode. Therefore, a study on electrochemical properties, determination of clozapine, and validation of applied voltammetric techniques were performed on bismuth film electrode. This study aims to examine the electrochemical properties of clozapine and to develop a sensitive electrochemical methodology for direct and rapid determination of clozapine from pharmaceutical formulations on bismuth film electrode using voltammetric techniques.

\section{MATERIAL AND METHODS}

\section{Reagents}

Clozapine and drug tablets are commercially available. A $1 \times 10^{-2} \mathrm{M}$ stock solution of clozapine was prepared in methanol and stored in the fridge. In all voltammetric studies, standard solutions were prepared by diluting the stock solutions with methanol. The suitability of $0.04 \mathrm{M}$ Britton-Robinson (pH 3.50-8.00) and 0.2 M acetate buffer (pH 3.50 - 8.00) as supporting electrolyte was investigated and acetate buffer was selected. Buffers and supporting electrolytes were prepared with $\mathrm{CH}_{3} \mathrm{COOH}$ (Reidel de Haen, $100 \%$ ), $\mathrm{H}_{3} \mathrm{PO}_{4}$ (Carlo Erba, 35\%), $\mathrm{H}_{3} \mathrm{BO}_{3}$ (Merck), $\mathrm{NaOH}$ (Reidel de Haen). Glassy carbon electrode was polished with slurries prepared from 1, 0.3 and, 0.05-micron size alumina powders and deionized water on the Buehler cloth. Also, argon gas (99\% purity), methanol, and deionized water were used without any purification. To prepare a bismuth-coated glassy carbon electrode, $100 \mathrm{ppm} \mathrm{BiCl}_{3}$ was prepared in $0.2 \mathrm{M} \mathrm{KCl}$ solution.

\section{Apparatus and Instrumentation}

Voltammetric studies were performed with $\mathrm{CH}$ Instruments $660 \mathrm{C}$ Model Potentiostat/Galvanostat. A triple electrode system formed bismuth coated glassy carbon electrode as a working electrode, $\mathrm{Ag} / \mathrm{AgCl}$ electrode as reference electrode and platinum wire as a counter electrode was used. All voltammetric responses were taken versus the $\mathrm{Ag} / \mathrm{AgCl}$ electrode. $\mathrm{pH}$ measurements were made with a PL-700PV model pH meter. The deionized water used in the preparation of the solutions was obtained from the Zeneer Power-Water Purification System. Measurements executed at ambient laboratory temperature.

Differential pulse voltammetry conditions were: Pulse amplitude, $50 \mathrm{mV}$; pulse width $50 \mathrm{~ms}$; scan rate, $20 \mathrm{mV} \mathrm{s}^{-1}$.

\section{The Procedure of Pharmaceutical Preparations}

The stock solution of $1 \times 10^{-2} \mathrm{M}$ clozapine was prepared daily in methanol. The standard solutions for the calibration study were prepared by diluting the appropriate volumes of these stock solutions. The measurements for individual concentration was repeated three times. After preparing the calibration graph $\left(10^{-5} \mu \mathrm{M}-1 \mu \mathrm{M}\right)$, the determination process was started from the drug tablet containing clozapine. Ten drug tablets (each tablet containing $25 \mathrm{mg}$ clozapine according to the label) were weighed and well ground to a fine powder. The stock solution containing $1 \times 10^{-2} \mathrm{M}$ clozapine in methanol was prepared in a $100 \mathrm{~mL}$ volumetric flask.

\section{RESULTS AND DISCUSSION}

\section{Preparation of Working Electrode}

Bismuth-coated glassy carbon electrode is used as a working electrode. The first step of the modification process is polishing a commercial glassy carbon electrode (GC). Therefore, the GC (CHI 104, $0.071 \mathrm{~cm}^{2}$ area) was polished successively in alumina slurries in which 1-, 0.3-, and $0.05 \mu \mathrm{m}$ alumina particles, respectively, as described previously [17]. The coating solution was $100 \mathrm{ppm} \mathrm{BiCl}_{3}$ solution in $0.5 \mathrm{M} \mathrm{KCl}$ supporting electrolyte. The aqueous medium was buffered with acetic acid/sodium acetate buffer solution. The coating step was performed to dip the GC in the coating solution and then apply the amperometric technique at $-1 \mathrm{~V}$ potential. The electrochemical characterization of the bismuth coated GC electrode was achieved by using $1 \mathrm{mM}$ dopamine and ferrocene solutions. The voltammograms for dopamine and ferrocene were demonstrated in Fig. 2 and Fig. 3, respectively.

When we compare the voltammetric results from both the bare GC and bismuth coated GC, it is distinguished that the electrode was successfully coated with bismuth. At the bare GC, there is only one anodic peak observed at about $0.5 \mathrm{~V}$ potential with an accompanying cathodic peak. These peaks belong to electrochemical oxidation and reduction of 


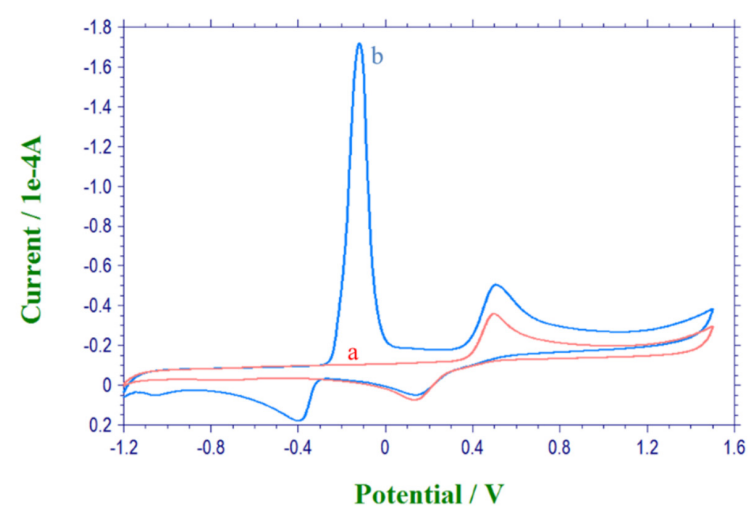

Figure 2. The cyclic voltammograms for $1 \mathrm{mM}$ dopamine solution in $0.5 \mathrm{M} \mathrm{NaCl}$ supporting electrolyte at a) the bare GC electrode and b) the bismuth coated GC (bismuth film) electrode (scan rate: $0.1 \mathrm{Vs}^{-1}$ ).

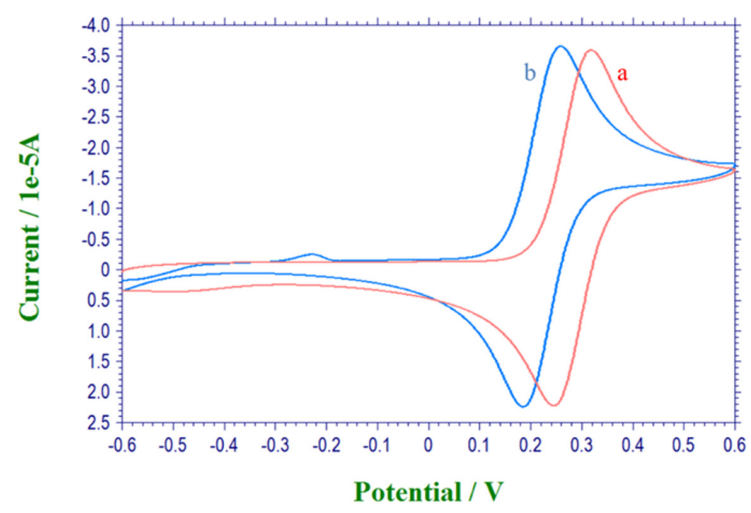

Figure 3. The cyclic voltammograms for $1 \mathrm{mM}$ ferrocene solution in $0.1 \mathrm{M}$ TBATFB supporting electrolyte in acetonitrile at a) the bare GC electrode and b) the bismuth coated GC (bismuth film) electrode (scan rate: $\left.0.1 \mathrm{Vs}^{-1}\right)$.

dopamine. On the other hand, one different anodic peak additionally shows up at about $-0.1 \mathrm{~V}$ potential, which is more negative than that of dopamine. This new narrow peak was attributed to the oxidation of bismuth on the GC surface (Fig. 2).

In addition to the dopamine test, the electrochemical behavior of ferrocene also supported the coating of GC with bismuth. Fig. 3 shows the cyclic voltammograms of $1 \mathrm{mM}$ ferrocene solutions. The first one belongs to the electrochemical oxidation of ferrocene at bare GC electrode. On the other hand, the second one represents the same reaction but at the bismuth coated GC electrode. As shown from the results, there are some differences between the two voltammograms. The oxidation potential shifted to a more negative value because of the surface change. This behavior gave a hint about the potential catalytic effect of bismuth. Besides, a new oxidation peak showed up at around $-0.2 \mathrm{~V}$ in the case of bismuth coated GC electrode. This potential is very near to the oxidation of bismuth on the surface. These results confirmed the modification of the GC electrode with bismuth and preparation of bismuth coated GC electrode.

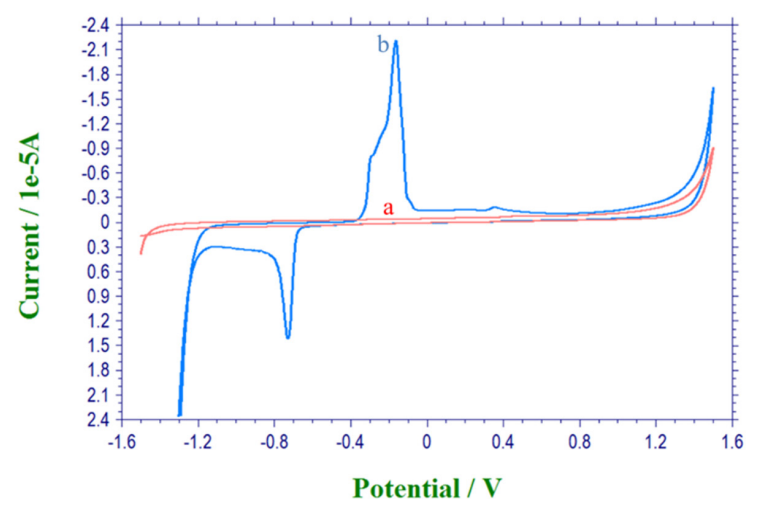

Figure 4. The cyclic voltammograms for $2 \mu \mathrm{M}$ clozapine solution in $0.2 \mathrm{M}$ acetate buffer $(\mathrm{pH}=5.00)$ solution at a) the bare $\mathrm{GC}$ electrode and b) the bismuth coated GC (bismuth film) electrode (scan rate: $0.1 \mathrm{Vs}^{-1}$ ).

\section{The Electrooxidation of Clozapine at Bismuth Modified GC Electrode}

The electrooxidation of clozapine was investigated using two different electrodes. When the peak currents of clozapine at bare GC and bismuth coated GC electrodes were compared, the calculation showed that the peak current for the modified electrode (bismuth coated GC) is approximately 75 times higher than that of bare GC electrode. This result demonstrated that the new modified electrode was more sensitive than the commercial GC electrode (Fig. 4).

\section{Determination of Optimum Conditions for Oxidation of Clozapine}

The effects of $\mathrm{pH}$ and supporting electrolyte on the oxidation potential and peak current were monitoring various conditions. First, the conditions for which the highest current was observed for the oxidation of clozapine were determined. Using differential pulse voltammetry (DPV) technique, the dependence of peak current and potential on $\mathrm{pH}$ was investigated in both acetic acid/acetate and Britton Robinson buffer solutions as a supporting electrolyte. The results are tabulated in Table 1 for acetate and BR buffer solutions.

The change in the peak current with $\mathrm{pH}$ was also plotted (Fig. 5) as well as peak potential (Fig. 6).

According to the results given in Table 1 and the behaviors observed in Fig. 5 and Fig. 6, the maximum peak current was $0.5958 \mu \mathrm{A}$ and obtained in an acetate buffer solution with a pH of 5 . Fig. 5 shows the effect of $\mathrm{pH}$ on the oxidation of clozapine. As seen from the figure, anodic peak potentials away from positive values as the $\mathrm{pH}$ values increase. This change occurred as the potential value decreased from $384 \mathrm{mV}$ to $216 \mathrm{mV}$ as the $\mathrm{pH}$ increased from 3 to $\mathrm{pH} 8$. This behavior shows that protons are involved in the electrode process. 
Table 1. Voltammetric results for the study of $\mathrm{pH}$ and buffer type effect on the electrochemical oxidation of clozapine ( $2 \mu \mathrm{M}$ clozapine, $0.2 \mathrm{M}$ acetate buffer, 0.04 M BR buffer)

\begin{tabular}{lllll}
\hline \multirow{2}{*}{$p H$} & \multicolumn{2}{c}{ Acetate Buffer } & \multicolumn{2}{c}{ BR Buffer } \\
\cline { 2 - 5 } & Current $(\mu A)$ & Potential $(V)$ & Current $(\mu A)$ & Potential $(V)$ \\
\hline 3.5 & 0.357 & 0.444 & 0.171 & 0.384 \\
5.0 & 0.596 & 0.320 & 0.380 & 0.328 \\
6.5 & 0.032 & 0.204 & 0.540 & 0.264 \\
8.0 & 0.583 & 0.080 & 0.489 & 0.216 \\
\hline
\end{tabular}

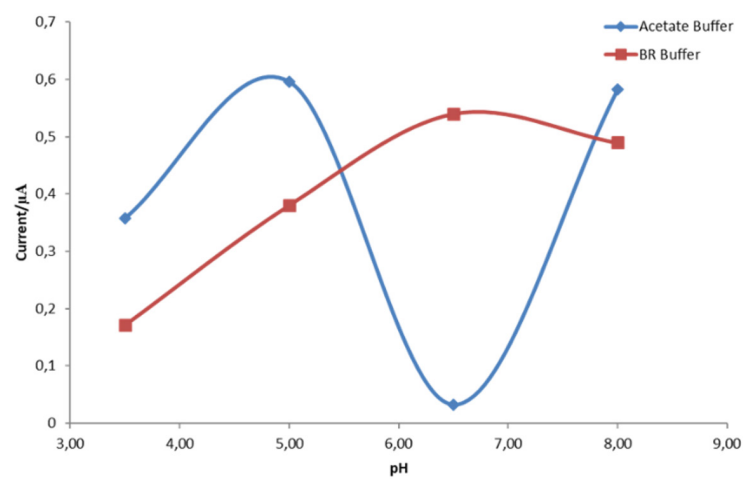

Figure 5. The effect of $\mathrm{pH}$ from different buffers on the peak current of $2 \mu \mathrm{M}$ clozapine solution.

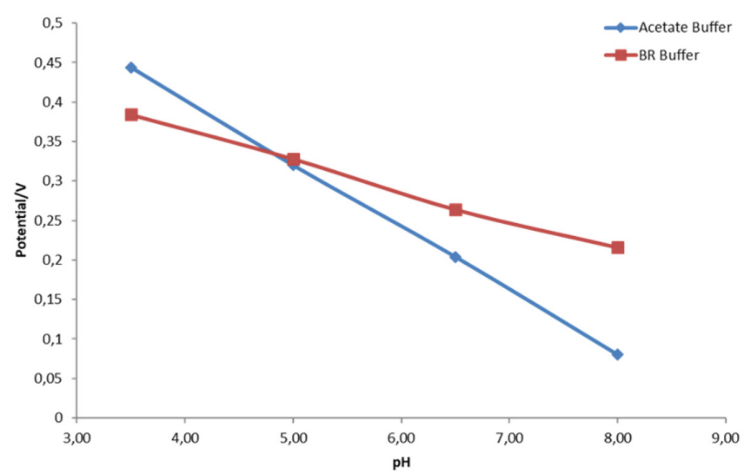

Figure 6. The effect of $\mathrm{pH}$ from different buffers on the peak potential of $2 \mu \mathrm{M}$ clozapine solution.

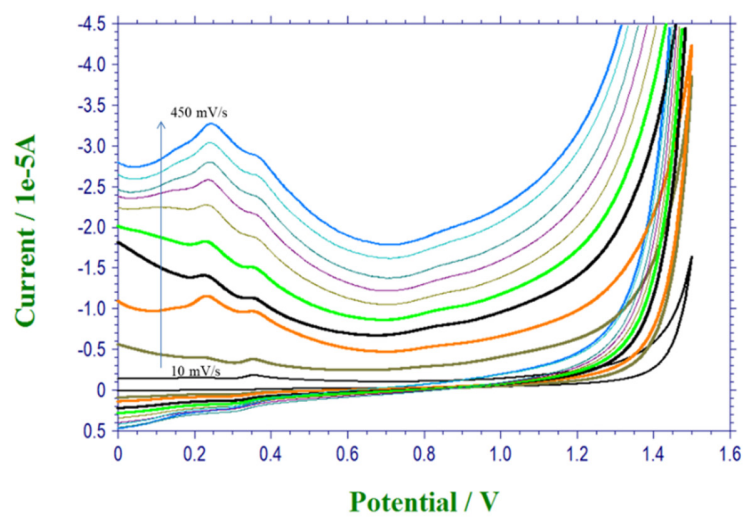

Figure 7. The cyclic voltammograms of $2 \mu \mathrm{M}$ clozapine for different scan rates from $10 \mathrm{mVs}^{-1}$ to $450 \mathrm{mVs}^{-1}$ at bismuth film electrode in $0.2 \mathrm{M}$ acetate buffer solution ( $\mathrm{pH}=5.00)$.

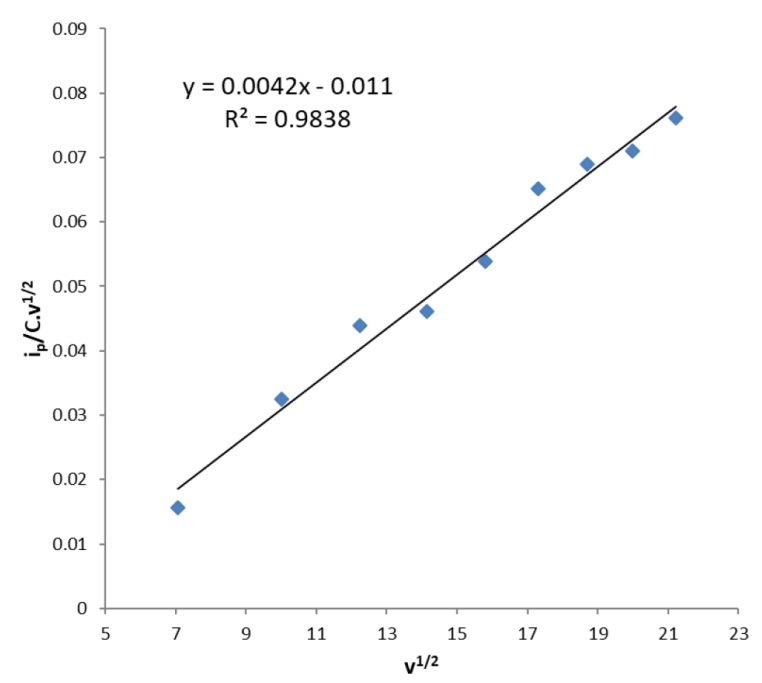

Figure 8. The dependence of current function $\left(\mathrm{Ip} / \mathrm{Cv}^{1 / 2}\right)$ to the square root of scan rate $\left(\mathrm{v}^{1 / 2}\right)$ from $\mathrm{CV}$ study of $2 \mu \mathrm{M}$ clozapine at bismuth film electrode in $0.2 \mathrm{M}$ acetate buffer solution $(\mathrm{pH}=5.00)$.

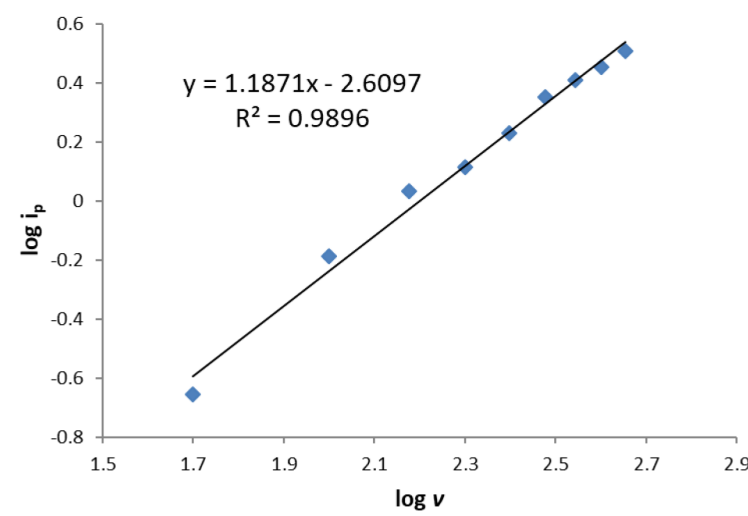

Figure 9. The $\log \mathrm{Ip}-\log \mathrm{v}$ curve from CV study of $2 \mu \mathrm{M}$ clozapine at bismuth film electrode in $0.2 \mathrm{M}$ acetate buffer solution $(\mathrm{pH}=5.00)$.

\section{The Variation of Current with The Scan Rate}

The oxidation of clozapine $(2 \mu \mathrm{M})$ has been investigated in acetate buffer solution ( $\mathrm{pH}=5.0)$ by using cyclic voltammetry $(\mathrm{CV})$. The voltammograms obtained from nine different scan rates between $50 \mathrm{mVs}^{-1}$ and $450 \mathrm{mVs}^{-1}$ were given in Fig. 7. In this range of scan rate values, there is a linear relationship between the square root of scan rate $\left(\mathrm{v}^{1 / 2}\right)$ and current function ( $\left.\mathrm{Ip} / \mathrm{Cv}^{1 / 2}\right)$. This behavior can be seen from Fig. 8 and shows that this is an adsorption controlled current. Furthermore, when the logarithm of the peak current and the scan rate is examined (Fig. 8), the slope is found to be 1.1834 , which is another criterion that the current is adsorption controlled [18].

\section{Determination of Analytical Working Range}

The analytical working range was determined according to the measurements obtained by the DPV technique in acetate $(\mathrm{pH}=5.00)$ buffer solution in the concentration range of $1 \mu \mathrm{M}-10 \mu \mathrm{M}$ (Fig. 10). Voltammograms at different concentrations for clozapine were recorded under 


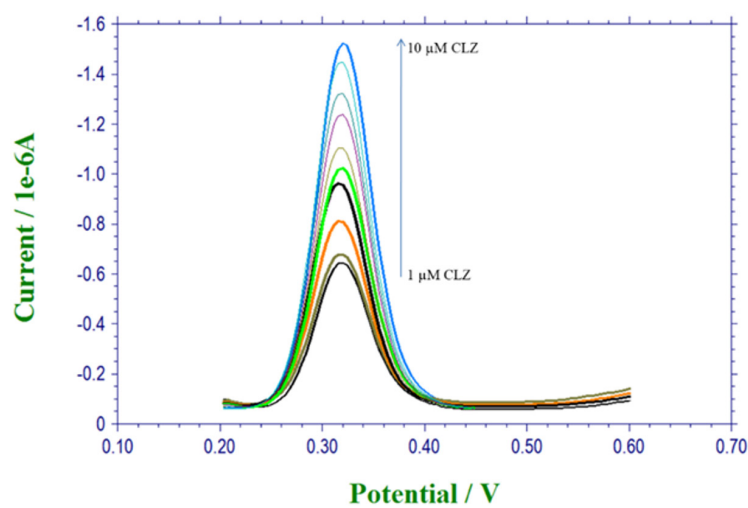

Figure 10. The differential pulse voltammograms of clozapine for different concentrations from $1 \mu \mathrm{M}$ to $10 \mu \mathrm{M}$ at bismuth film electrode in 0.2 $\mathrm{M}$ acetate buffer solution ( $\mathrm{pH}=5.00)$.

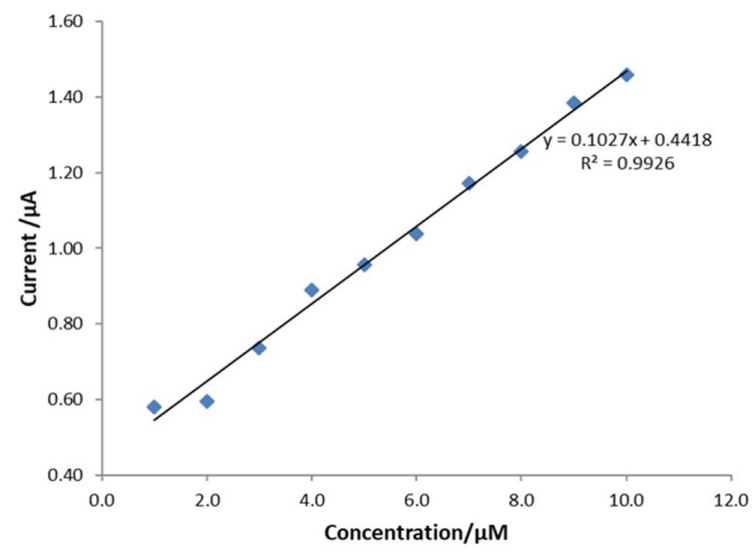

Figure 11. The calibration graph for determination of clozapine at bismuth film electrode in $0.2 \mathrm{M}$ acetate buffer solution $(\mathrm{pH}=5.00)$.

optimal analytical conditions. For clozapine, a calibration curve with high linearity was obtained in this medium in the range of $1 \mu \mathrm{M}-10 \mu \mathrm{M}$ (Fig. 11).

According to the equations, $\mathrm{LOD}=3 \mathrm{~s} / \mathrm{m}$ and $\mathrm{LOQ}=10$ $\mathrm{s} / \mathrm{m}$, the limit of detection and the limit of quantitation were calculated using measured peak currents, respectively. Where "s" is the standard deviation of peak currents (for three measurements) and " $\mathrm{m}$ " is the slope of the calibration curve [19]. LOD and LOQ were calculated as $6.112 \times 10^{-9}$ $\mathrm{mol} / \mathrm{L}$ and $2.0373 \times 10^{-8} \mathrm{~mol} / \mathrm{L}$ for bismuth-modified glassy carbon electrodes, respectively (Table 2).

On the other hand, there are several references in the literature about the determination of CLZ. The results of these methods as well as that of the present study are given in Table 3. Table 3 contains the information about these studies such as working electrodes, the techniques used, the linear ranges, and LOD.

\section{Analytical Application and Recovery Study}

Commercial drug tablets containing $25 \mathrm{mg}$ of clozapine per tablet were exactly weighed and ground to a fine
Table 2. Analytical parameters of the calibration graph for differential pulse voltammetric determination of clozapine at bismuth film electrode in $0.2 \mathrm{M}$ acetate buffer solution $(\mathrm{pH}=5.00)$

\begin{tabular}{ll}
\hline \multicolumn{1}{c}{ Parameters } & \multicolumn{1}{c}{ Results } \\
\hline Linear concentration range, mol/L & from $1 \times 10^{-6}$ to $10 \times 10^{-6}$ \\
Slope, $\mu A M^{-1}$ & 0.10274 \\
SD of slope & 0.00314 \\
The correlation coefficient, $r$ & 0.9963 \\
Regression standard deviation, sr & $2.850 \times 10^{-8}$ \\
Number of measurements & 3 \\
$L O D$, mol $L^{-1}$ & $6.112 \times 10^{-9}$ \\
$L O Q$, mol $L^{-1}$ & $2.0373 \times 10^{-8}$ \\
\hline
\end{tabular}

Table 3. The comparison of different studies in the literature with the present study for voltammetric determination of CLZ

\begin{tabular}{llll}
\hline$W E$ & Technique & LinearRange & LOD \\
\hline HMDE & SWAdCS & $1.0-3.3 \mathrm{nM}$ & $0.45 \mathrm{nM}$ \\
$\mathrm{TiO}_{2} \mathrm{NP} / \mathrm{MCPE}$ & $\mathrm{AD}-\mathrm{DPV}$ & $0.5-45 \mu \mathrm{M}$ & $61.00 \mathrm{nM}$ \\
PPY/CNT/GCE & LSV & $0.01-5.00 \mu \mathrm{M}$ & $3.00 \mathrm{nM}$ \\
$\mathrm{EPGCE}$ & $\mathrm{AdSV}$ & $0.1-1 \mu \mathrm{M}$ & $8.00 \mathrm{nM}$ \\
$\mathrm{F}_{3} \mathrm{O}_{4} / \mathrm{Ala} / \mathrm{Pd} / \mathrm{GCE}$ & $\mathrm{DPV}$ & $3-70 \mathrm{nM}$ & $1.53 \mathrm{nM}$ \\
$\mathrm{RU} / \mathrm{TiO} / \mathrm{CPE}$ & $\mathrm{SWV}$ & $0.9-40 \mu \mathrm{M}$ & $0.43 \mathrm{nM}$ \\
$\mathrm{Bi} / \mathrm{GCE}$ & $\mathrm{DPV}$ & $1-10 \mu \mathrm{M}$ & $6.11 \mathrm{nM}$ \\
\hline
\end{tabular}

WE: Working Electrode, HMDE: hanging Mercury Drop Electrode NP: Nanoparticles, MCPE: Modified Carbon Paste Electrode, PPY: PolyPyrrole, CNT: Carbon Nanotube, GCE: Glassy Carbon Electrode, EP: Electrochemically Pretreated, SWAdCS: Square Wave Adsorptive Cathodic Stripping, AD-DPV: Adsorptive Differential Voltammetry, LSV: Linear Sweep Voltammetry

powder. A stock solution of concentration $1 \times 10^{-2} \mathrm{~mol} / \mathrm{L}$ was prepared by weighing the appropriate amount of the powdered solid and dissolving it in methanol. Appropriate solutions were prepared by taking proper volumes of the stock solution and diluting with $0.2 \mathrm{~mol} / \mathrm{L}$ acetic acid/ sodium acetate buffer solution used as supporting electrolyte. The quantity of clozapine in the trading tablet was calculated as $25.3 \pm 2.2 \mathrm{mg}$ using the calibration equation.

Besides, a recovery test was performed for the developed method, and the results are given in Table 5. According to the results, the new analytical method has shown that tablets can be applied successfully without any intervention in the determination of clozapine. When the amount of clozapine was added, and the amount of clozapine detected was compared, recovery from the commercial tablets was found to be $97.00 \%$.

\section{CONCLUSION}

In this study, the electrochemical oxidation property of clozapine on the bismuth coated glassy carbon electro- 
Table 4. Result for the determination of clozapine in a drug dosage form

\begin{tabular}{llll}
\hline Drugform & Declared & Found $a / m g$ & RSD, \% \\
\hline Tablet & 25 mgpertablet & $25.3 \pm 0.3$ & 1.2 \\
\hline
\end{tabular}

Table 5. Recovery study for the determination of clozapine in a drug tablet

\begin{tabular}{lllll}
\hline Sample & Spiked & Found & $\begin{array}{l}\text { Recovery, } \\
\%\end{array}$ & RSD, \% \\
\hline Drug tablet & $6.536 \times 10-3 \mathrm{mg}$ & $6.363 \times 10^{-3} \mathrm{mg}$ & 97 & 1.32 \\
\hline
\end{tabular}

de was investigated by using DPV and CV techniques. Oxidation peaks between $0.3 \mathrm{~V}$ and $0.6 \mathrm{~V}$ were determined on voltammograms taken with acetate buffers $(\mathrm{pH}$ 3.50-8.00) at different $\mathrm{pH}$ values. Voltammograms were obtained by using the DPV technique in different electrolytes selected in acidic and basic regions. The working medium was determined according to the obtained $\mathrm{pH}$ Ip change.

When the peak currents of clozapine in the glassy carbon electrode $(0.330 \mu \mathrm{A})$ and modified electrode $(21.69 \mu \mathrm{A})$ are compared, the peak current at the modified electrode is about 70 times higher, indicating that the modified electrode is more sensitive than the bare GC electrode. As a result, this study suggests a new method for the determination of CLZ. As seen from Table 3 some different methods and electrodes have been used for the determination of CLZ but it is the first time to use the bismuth modified carbon electrode for this purpose. The linear range and LOD of this method are near the other methods.

\section{ACKNOWLEDGEMENT}

The authors would like to express their gratitude to Selehattin Yllmaz, who provided the drug active substance.

\section{References}

1. Mohamed A, Sheikka MA. Spectrophotometric determination of clozapine based on its oxidation with bromate in a micellar medium. IL Farmaco, 59 (2004) 907. DOI: 10.1016/j.farmac.2004.07.008.

2. Hammam E, Tawfik A, Ghoneim AA. Adsorptive stripping voltammetric quantification of the antipsychotic drug clozapine in bulk form, pharmaceutical formulation and human serum at a mercury electrode. Journal of Pharmaceutical Biomedical Analysis 36 (2004) 149. DOI: 10.1016/j.jpba.2004.04.012.

3. Güven FM, Birsöz S. Klozapin ve Şizofreni Sağaltımındaki Yeri. Klinik Psikiyatri 4 (2001) 124-128.

4. Lieberman JA, Saltz BL, Johns CA, Pollack S, Borenstein M, Kane J. The effects of clozapine on tardive dyskinesia. The British Journal of Psychiatry 158 (1991) 503. DOI: 10.1192/bjp.158.4.503.

5. Freudenreich O, Henderson DC, Walsh JP, Culhane M.A., Goff DC. Risperidone augmentation for schizophrenia partially responsive to clozapine: A double-blind, placebo-contolled trial. Schizophrenia
Research 92 (2007) 90. DOI: 10.1016/j.schres.2006.12.030

6. Guitton C, Kinowski JM, Regis A., Bressolle F. Determination of clozapine and its major metabolites in human plasma and red blood cells by high-performance liquid chromatography with ultraviolet absorbance detection. Journal of Chromatography B 690 (1997) 211222. DOI: 10.1016/S0378-4347(96)00362-3.

7. Taha EA, Soliman SM, Abdellatef HE, Ayad MM. Colorimetric methods for the determination of some tricyclic antidepressant drugs in their pure and dosage forms, Mikrochimica Acta 140 (2002) 175-182. DOI:10.1007/s00604-002-0904.

8. Gosser Jr. DK, Cyclic Voltammetry: Simulation and analysis of reaction mechanisms, VCH Publishers, New York, 1983, ISBN: 9781560810261 .

9. Mashhadizadeh $\mathrm{MH}$, Afshar E. Electrochemical investigation of clozapine at $\mathrm{TiO}_{2}$ nanoparticles modified carbon paste electrode and simultaneous adsorptive voltammetric determination of two antipsychotic drugs. Electrochimica Acta 87 (2013) 816. DOI: 10.4103/2229-5186.79345.

10. Weber JM, Volke J. 75 years in the polarography of pharmaceuticals and physiologically active substances. Pharmazie 46 (1991) 853.

11. Edno L, Combourieu I, Cazenave M, Tignol J. Assay for quantitation of clozapine and its metabolite N-desmethyl clozapine in human plasma by high performance liquid chromatography with ultraviolet detection. Journal of Pharmaceutical and Biomedical Analysis 16 (1997) 311. DOI: 10.1016/s0731-7085(97)00048-4.

12. Raggi MA, Bugamelli F, Mandrioli R, Sabbioni C, Volterra V, Fanali S. Rapid capillary electrophoretic method for the determination of clozapine and desmethylclozapine in human plasma, Journal of Chromatography A 916 (2001) 289-296. DOI: 10.1016/S00219673(01)00520-9.

13. Elqudaby HM, Mohamed GG, El-Din GMG. Electrochemical behaviour of trimebutine at activated glassy carbon electrode and its direct determination in ürine and pharmaceutics by square wave and differential pulse voltammetry. International Journal of Electrochemical Science 9 (2014) 856-869.

14. DemirbilekE, Saglıkoglu G, Yılmaz S. Electrochemicalinvestigation of isoniazid on poly ( $\mathrm{p}$-aminobenzene sulfonic acid) film modified glassy carbon electrode. International Journal of Electrochemical Science 10 (2015) 4428-4438.

15. Shahrokhian S, Kamalzadeh Z, Hamzehloei A. Electrochemical determination of clozapine on MWCNTs/New coccine doped PPY modified GCE: An experimental design approach, Bioelectrochemistry 90 (2013) 36. DOI: 10.1016/j. bioelechem.2012.10.002.

16. Tammari E, Neshadali A, Lotfi S, Veisi H. Fabrication of an electrochemical sensor based on magnetic nanocomposite $\mathrm{Fe}_{3} \mathrm{O}_{4} / \beta$ Alanine/Pd modified glassy carbon electrode for determination of the nanomolar level of clozapine in biological model and pharmaceutical samples. Sensors and Actuators B: Chemistry 241 (2017) 879. DOI: 10.1016/j.snb.2016.11.014.

17. Gökmeşe F, Gökmeşe E, Emire Z. A simple and rapid method for preparing carbon nanopore electrode ensemble coating a glassy carbon electrode with chromate. Hittite Journal of Science and Engineering 3 (2016) 1. DOI: 10.17350/HJSE19030000025.

18. Bard AJ, Faulkner LR. Electrochemical Methods; Fundamentals and Applications. John Wiley and Sons, Inc., New York, 2001, ISBN: 0-471-04372-9, page 833.

19. Shrivastava A., Gupta VB. Methods for the determination of limit of detection and limit of quantitation of the analytical methods. Chronicles of Young Scientists 2 (2011) 21. DOI: 10.4103/22295186.79345 .

20. K. Farhadi, A. Karimpour, Electrochemical behavior and 
determination of clozapine on a glassy carbon electrode modified by electrochemical oxidation, Anal. Sci. 23, (2007) 479.

21. N.P. Shetti, D.S. Nayak, S.J. Malode, R.M. Kulkarni, An electrochemical sensor for clozapine at ruthenium doped $\mathrm{TiO}$ nanoparticles modified electrode, Sensors and Actuators B: Chem., 247 (2017) 858. 